\title{
Advantages of the Introduction of Electronic Healthcare Prescriptions before COVID Era Experiences in Pioneer Countries Estonia and Finland and the Status in Germany
}

\section{Ch. Racek (Christoph Racek), A. Czirfusz (Attila Czirfusz)}

SEUC PhD program in Health management and public health, Germany.

\section{E-mail address:}

christophracek@gmx.net

\section{Reprint address:}

Christoph Racek

SEUC PhD Program in Health Management and Public Health

Dentist

Winzerstr. 28

79227 Schallstadt

Germany

Source: Clinical Social Work and Health Intervention

Volume: 12

Issue: 2

Pages: 39 - 44

Cited references: 21

\section{Reviewers:}

Andrea Shahum,

University of North Carolina at Chapel Hill School of Medicine, USA

Steve Szydlowski

University of Scranton school of education, USA

\section{Keywords:}

Functions of e-prescription. eHealth. Benefits of e-prescription, e-prescription Implementation Barriers. Patients Safety.

\section{Publisher:}

International Society of Applied Preventive Medicine i-gap

CSWHI 2021; 12(2): 39 - 44; DOI: 10.22359/cswhi_12_2_07 (C) Clinical Social Work and Health Intervention

\section{Abstract:}

\begin{abstract}
As pointed out by previous studies, fragmentation of health information based on medical prescription is a prevalent health crisis across the globe. Several countries such as Finland, Estonia, and Germany have adopted the electronic health system to eradicate these medical errors ${ }^{1}$. As suggested by the health professionals, the major health concerns in modern healthcare are prescription error elimination and patients' safety. So, eprescription is proposed as the most effective health approach to provide long-term solutions by replacing manually written
\end{abstract}

\footnotetext{
${ }^{1}$ Greenhalgh, T., Stones, R. (2010). Theorizing big IT programs in healthcare: Strong structuration theory meets actor-network theory. Social Science and Medicine 70 (9), 1285-1294.
} 
prescriptions ${ }^{2}$. Electronic health is a computerized medical system with an expansive database of patients' information. Despite its speculated benefits on the health industry, e-prescription implementation has experienced various challenges such as patients and pharmacists resistance ${ }^{3}$. Therefore, this paper explores the health benefits of e-prescriptions in Estonia and Finland and their status in Germany.

\section{Function of the e-prescription}

\section{Capabilities of education}

Full details of the patients' medical history are provided by the e-prescription. Supplying the medical providers with knowledgeable information about the patients is easy for improving the quality of healthcare services. Additionally, eprescription is web-based and the patients and team of healthcare providers can interact and socialize online to educate patients on health issues.

\section{Improves efficiency}

As suggested by experts, the implementation of e-prescription is safe and faster ${ }^{4}$. Transition from the huge paperwork in issuing prescriptions to electronic print is more efficient and faster in retrieving the right medication for the patient. Besides, the long queuing at the health centers is minimized since services of e-prescription are much faster compared to physical handwriting 5 . More than that, reduced errors which could lead to health dangers are not embedded within the eprescription hence this justifies its efficiency.

\section{Expansion of patient medication adherence}

E-prescription frameworks can assist doctors with picking a minimal effort choice that might be clinically better for the patient. This is practical by eliminating inclination increased adherence to prescription treatment can advance better health results and diminish costs. At the drug store, the entering of solutions is more smoothed out when programming takes into consideration robotized preparation $^{6}$. Alongside medicine adherence, the replacement of non-exclusive meds or less exorbitant model options can decrease the expense to patients and insurance agencies. An expansion ineffectiveness is seen in the wake of executing e-recommending, principally because of less administrative work and fewer issues waiting to be settled.

\section{Advantages of this digital form: Store and display full patient-specific considerations, patient demographics, and structured patient data}

Joining e-prescription during the time spent on medical care can improve the nature of care productively. A medical services association needs to enlist individuals for different jobs like recording or deciphering ${ }^{7}$. It fundamentally decreases the danger of blunders and false impressions that can antagonistically influence the nature of care. The degree of the nature of care has expanded altogether because of the utilization of e-prescription. Business costs can deplete income. Notwithstanding, with e-prescription, you can dispose of the greater part of the recording assignments. Specialists can in any event diminish them to a point where staff hours can be decreased $^{8}$. Electronic prescription is regularly simpler to peruse than a specialist's penmanship.

\footnotetext{
${ }^{2}$ Cornford, T., Hibberd, R., Barber, N. (2014). The evaluation of the electronic prescription service in primary care, Technical Report.

${ }^{3}$ Uemo. (2019). Finland And Estonia Pioneering Cross-Border Health Services - Uemo. Uemo. Eu.

${ }^{4}$ HIMSS Europe. (2018). HIMSS Analytics Annual European eHealth Survey 2018.

${ }^{5}$ Helsinki,.(2013). eHealth Strategy And Action Plan Of Finland In A European Context.

${ }^{6}$ Lillevali, A., Kond, K, (2019).E-Prescription Success In Estonia: The Journey From Paper To Pharmacogenomics.

${ }^{7}$ Tinyakov, S. (2018). The priorities for health and social care policy in Germany

${ }^{8}$ Noventi. (2019). We Are Ready For E-Prescription. NOVENTI. https://www.noventi.de/en/news/we-areready-for-e-prescription.
} 


\section{Quick and safe retrieval of patients' data}

Electronic prescription is faster in accessing patients' data compared to offline data. It essentially decreases the danger of blunders and false impressions that can unfavorably influence the nature of care. Joining e-prescription during the time spent on medical care can improve the nature of care effectively ${ }^{9}$. Also, record costs are typically decreased because the framework translates predefined notes or documentation made by the doctor during a patient visit by basically barring the requirement for a staff transcriptionist. The degree of nature of care has expanded essentially because of the utilization of e-prescription. Automated information is frequently simpler to peruse than a specialist's penmanship.

\section{Ability to recruit a new breed of physicians}

Young graduates from medical schools are familiar with the digital system, unlike the older medical professionals. Adopting the digital system within the healthcare sector will provide more opportunities for fresh graduates to fill these newly created spaces by the e-prescription ${ }^{10}$. Implementation intention of the e-prescription calls for the new breed of doctors who are more conversant with the digital world to replace the analogue generations in adopting the new changes within the medical sector. New specialists look for training to grow another way, and the innovation offered in an e-prescription is something they have become constant to in residency. Electronic prescription makes occupations simpler and more productive thus disclose to them that training is developing and staying aware of industry changes.

\section{Reduced bulky paperwork}

An Offline medical prescription involves extreme use of paperwork that accumulates over the years in the office. Electronic prescription disposes of the need to store reports in massive file organizers ${ }^{11}$. Not exclusively is restricted space currently utilized for another capacity of the workplace, however innumerable office supplies like paper, dividers, and graph costs are dispensed with. Paper outlines and notes can occupy a ton of room. What's more, as they develop, it gets urgent to discover substitute storerooms for more established outline volumes. In any case, with e-prescription, specialists can supplant paper outlines.

\section{Implementation in Estonia and Finland}

Implementation of e-prescription in Finland and Estonia has generated various health benefits to patients and health providers ${ }^{12}$. The absence of sufficient patients' information has been a great challenge in Estonia and Finland hence causing health dangers to patients. The introduction of electronic prescription in Finland and Estonia has offered medical providers and patients a better experience by providing a broad range of health information on a national scale. Elderly patients in Estonia and Finland are no longer exposed to health risks due to the fragmentation of health information. Now, other countries are in the process of e-prescription implementation to create a national electronic medical approach just like Finland and Estonia. Several countries like Germany which have faced dismantled implementation attempts at initial stages are intending to offer a flexible and accurate updated dispensed and prescribed medication for every patient ${ }^{13}$. However, even Finland and Estonia experienced the slow process of e-prescription just like in Germany. In all countries, the common hurdles like e-prescription acceptance between patients and healthcare providers were witnessed ${ }^{14}$.

9 TFHC. (2019).E-Health In Germany

${ }^{10}$ Kela. 2020. Estonian Citizens Can Now Purchase Medicines In Finland With An E-Prescription Issued In Their Own Country - News Archive For Customers.

${ }^{11}$ Helsinki,.(2013). eHealth Strategy And Action Plan Of Finland In A European Context

${ }^{12}$ Cripps, H., Standing, C., Prijatelj, V. (2011). The Implementation of Electronic Health Records: A Two Country Comparison. In: Proceedings of BLED 2011, paper 46.

${ }^{13}$ Gohlisch, J. (2018). Digital Health in Germany - 2018 and beyond . Opgehaald van Medium: https://medium.com/@jangohlisch/digital-health-in-germany-2018-and-beyond-2b2df6032688

${ }^{14}$ Boonstra, A., Boddy, D., Fischbacher, M. (2004). The limited acceptance of an electronic prescription system by general practitioners: reasons and practical implications. New Technology, Work and Employment 19 (2), 128-144. 


\section{Reasons for the delay of the introduction in Germany}

Despite Estonia and Finland enjoying numerous benefits of e-prescription, Germany had a rough course in the implementation process of eprescription. The process of digitizing Germany's healthcare has been in delay due to several factors. Implementation intention of the e-prescription in Germany faced numerous hurdles as indicated by the Federal Health Ministry of Germany. Finally, the establishment of e-prescription in Germany was stabilized in the year 2020 after having encountered several failure stages.

\section{Reasons for the delay of e-prescriptions introduction in Germany:}

System errors associated with e-prescription: In Germany, the system errors or e-prescription was visible very early within the test regions ${ }^{15}$. It caused distrust and criticisms among the patients and healthcare providers ${ }^{16}$ concerning its efficiency. This inaccurate experience with e-prescription in the initial stages demonstrates inflexibility connected with digital medical platform. More than that, patients and medical providers in the first phase of e-prescription implementation experienced delays in the process of rendering prescriptions.

Legal and privacy issues: Most of the health recipients in Germany were opposed to the e-prescriptions due to the fear of legal and privacy issues. In Germany, most of the patients are used to offline prescriptions and the use of e-prescriptions demanded too much of their information including the bank details which triggered the uneasiness. For example, the e-prescriptions is web- based as it entails wires transmission of information $^{17}$. But as cyber-crimes are a prevalent issue with the digital platform, German citizens massively were against the implementation of the eprescription. Electronic prescription is open to information leakages at various points and if intrusion and firewall prevention systems are not properly installed, the privacy of patients' information is at risk. Several attempts of e-prescriptions tests in Germany proved to be insecure due to various errors hence the patients preferred to use offline prescription.

Inadequate time-frame for implementation: The Federal Health Ministry for Germany under-estimated the time process to transition from the analogue to digital medical prescription $^{18}$. As suggested by the research experts, medical providers and patients were not given enough time to adjust that quickly to e-prescriptions ${ }^{19}$. In most cases, the delays and errors witnessed through the e-prescription implementation process proved to be a result of improper timing for the program. Additionally, the scope of attitude change between health providers and patients was not taken seriously as the government thought the process of implementation could smooth just like in other countries like Finland and Estonia. Patients in Germany are used to the paperwork way of medical prescription hence eprescription was not popular ${ }^{20}$.

Lack of an integrated system accommodating various designs of healthcare departments: A potential stepwise acknowledgment of the general engineering - with putting away information just on the card in the initial step and the telematics foundation in a second was de-

${ }^{15}$ Engberg, Anna. 2019. German Health Minister Spahn Promotes Use Of Eprescriptions At The DMEA 2019. Healthcare IT News. https://www.healthcareitnews.com/news/emea/german-health-minister-spahn-promotes-use-eprescriptions-dmea-2019.

${ }^{16}$ Bastholm Rahmner, P. et al. (1994). Physicians' perceptions of possibilities and obstacles prior to implementing a computerized drug prescribing support system. International Journal of Health Care Quality Assurance 17(4), 173-179.

${ }^{17}$ Eversana. 2020. Germany To Mandate E-Prescriptions By 2022 I EVERSANA. Eversana. https://www.eversana.com/2020/04/02/germany-eprescriptions/.

${ }^{18}$ Dwivedi, Y. K. et al. (2014). Research on information systems failures and successes: status update and future directions. Information Systems Frontiers

${ }^{19}$ Duennebeil, S. et al. (2009). Integration of Patient Health Portals into the German Healthcare Telematics Infrastructure. In: Proceedings of AMCIS 2009, paper 754.

${ }^{20}$ Taylor Wessing. (2016, March). E-Health Law in Germany. Opgehaald van Synapse Law for Life Science 
serted or not considered ${ }^{21}$. The general design additionally might have been stepwise enhanced by point by point project results. During the intercession's advancement, it might have served to educate about changes in the to-be engineering because of postponements or different challenges. These means required complex parts and the inclusion of different equal advancement projects performed by countless sellers. Toward the end, the stepwise acknowledgment was important because of deferrals in understanding the telematics framework. The general design might have had a managing and recognizing capacity for every one of the many after tasks, advising similarly sellers and wellbeing suppliers.

\section{Conclusion}

Globally, healthcare organizations are shifting gradually from manually written prescriptions to e-prescription. The evolution of the modern healthcare system is gravitating towards the benefits of e-prescription due to reduce patients' information errors. For instance, in Finland, Estonia, and Germany, e-prescription is currently rated as the primary objective within their electronic health approaches ${ }^{22}$. However, the implementation process in all countries has been slower than expected due to resistance from patients and a team of healthcare providers. Besides, political interests, security, and privacy requirements are pointed out as the root to the implementation barriers.

\section{References}

1. BASTHOLM RAHMNER P et al. (1994) Physicians' perceptions of possibilities and obstacles prior to implementing a computerized drug prescribing support system. International Journal of Health Care Quality Assurance 17(4), pp 173-179.

2. BOONSTRA A, BODDY D, FISCHBACHER M (2004) The limited acceptance of an electronic prescription system by general practitioners: reasons and practical implications. New Technology, Work and Employment 19 (2), pp 128-144.
3. COMMONWEALTH FUND (2014) Germany: Health System Review. Health Systems in Transition, 20.

4. CRIPPS H, STANDING C, PRIJATELJ V (2011) The Implementation of Electronic Health Records: A Two Country Comparison. In: Proceedings of BLED 2011, paper 46.

5. CORNFORD T, HIBBERD R, BARBER N (2014). The evaluation of the electronic prescription service in primary care, Technical Report.

6. DUENNEBEIL S et al. (2009) Integration of Patient Health Portals into the German Healthcare Telematics Infrastructure. In: Proceedings of AMCIS 2009, paper 754.

7. DWIVEDI Y K et al. (2014) Research on information systems failures and successes: status update and future directions. Information Systems Frontiers.

8. ENGBERG A (2019) German Health Minister Spahn Promotes Use Of E-prescriptions At The DMEA 2019. Healthcare IT News. https://www.healthcareitnews.com/news/eme a/german-health-minister-spahn-promotesuse-eprescriptions-dmea-2019.

9. EVERSANA (2020). Germany To Mandate E-Prescriptions By 2022 / EVERSANA. Eversana.

https://www.eversana.com/2020/04/02/germany-eprescriptions/.

10. GOHLISCH J (2018) Digital Health in Germany-2018 and beyond. Opgehaald van Medium: https://medium.com/@jangohlisch/digital-health-in-germany-2018-andbeyond-2b2df6032688.

11. GREENHALGH T, STONES R (2010) Theorizing big IT program in healthcare: Strong structuration theory meets actor-network theory. Social Science and Medicine 70 (9), pp 1285-1294.

12. HELSINKI, (2013) eHealth Strategy And Action Plan Of Finland In A European Context. Retrievable from:https://www.google.com/ url?sa $=\mathrm{t} \& \mathrm{rct}=\mathrm{j} \& \mathrm{q}=\& \mathrm{esrc}=\mathrm{s} \&$ source $=$ web $\& \mathrm{c}$ $\mathrm{d}=\& \mathrm{cad}=$ rja\&uact $=8 \&$ ved $=2$ ahUKEwjRi JeZ-87uAhVTUBUIHciIBEkQFjAGegQI-

\footnotetext{
${ }^{21}$ Commonwealth Fund. (2014). Germany: Health System Review. Health Systems in Transition, 20.

${ }^{22}$ HIMSS Europe. (2018). HIMSS Analytics Annual European eHealth Survey 2018. Opgehaald van HIMSS Europe
} 
BRAC\&url=https $\% 3 \mathrm{~A} \% 2 \mathrm{~F} \% 2 \mathrm{Fjulkaisut} . v a l t$ ioneuvosto.fi $\% 2$ Fbitstream $\% 2$ Fhandle $\% 2 \mathrm{~F} 1$ 0024\%2F74720\%2FRAP2013_11_EHTEL_ verkko.pdf\%3Fsequence\%3D1\&usg=AOvVaw1eKRGFiLDrovuq37jZfaWl.

13. HIMSS EUROPE (2018) HIMSS Analytics Annual European eHealth Survey 2018. Opgehaald van HIMSS Europe: https://www. himss.eu/himss-analytics-annual-europeanehealth-survey-2018\#2018-form.

14. KELA (2020) Estonian Citizens Can Now Purchase Medicines In Finland With An EPrescription Issued In Their Own Country News Archive For Customers. Kela. En. https://www.kela.fi/web/en/news-archive//asset_publisher/1N08GY2nIrZo/content/estonian-citizens-can-now-purchase-medicines-in-finland-with-an-e-prescription-issuedin-their-own-country.

15. NOVENTI (2019) We Are Ready For E-Prescription. NOVENTI. https://www.noventi. de/en/news/we-are-ready-for-e-prescription .

16. LILLEVALI A, KOND K (2019) E-Prescription Success In Estonia: The Journey From Paper To Pharmacogenomics. Retrievable from: https://www.google.com/url?sa=t\&rct $=\mathrm{j} \& \mathrm{q}=\&$ esrc $=\mathrm{s} \&$ source $=$ web $\& \mathrm{~cd}=\& \mathrm{cad}=\mathrm{rja}$ \&uact $=8 \&$ ved $=2$ ahUKEwjA6pPU5c7uAhU M8hoKHYRAADYQFjACegQIARAC\&url $=$ https $\% 3 \mathrm{~A} \% 2 \mathrm{~F} \% 2 \mathrm{Fapps}$.who.int $\% 2$ Firis $\% 2$ Fbitstream $\% 2$ Fhandle $\% 2 F 10665 \% 2 F 332593$ \%2FEurohealth-25-2-18-20-eng.pdf\&usg= AOvVaw1FVsGYyKctO-tTqrUjkmdD.

17. WESSING T (2016) E-Health Law in Germany. Opgehaald van Synapse Law for Life Science: https://united-kingdom.taylorwessing.com/synapse/ti-ehealth-law-germany. html

18. TFHC (2019) E-Health In Germany. Retrievable from::https:/www.google.com/url? $\mathrm{sa}=\mathrm{t} \& \mathrm{rct}=\mathrm{j} \& \mathrm{q}=\& \mathrm{esrc}=\mathrm{s} \&$ source $=$ web $\& \mathrm{~cd}=$ $\&$ cad $=$ rja\&uact $=8 \& v e d=2$ ahUKEwj4kKjw8 c7uAhUSSxUIHezzCLEQFjACegQIB-

BAC\&url=https $\% 3 \mathrm{~A} \% 2 \mathrm{~F} \% 2 \mathrm{Fwww} . \mathrm{tfhc} . \mathrm{nl} \%$ 2Fwp-content $\% 2$ Fuploads $\% 2 F 2019 \% 2 \mathrm{~F} 08$ $\% 2 \mathrm{FeHealth}$-in-Germany-barriers-and-opportunities.pdf\&usg=AOvVaw27A9bPI8FuNz157aR2oiI.

19. TINYAKOV S (2018) The priorities for health and social care policy in Germany. Retrievable from:https://www.openaccess- government.org/health-and-social-care-germany $/ 52305 /$.

20. RADI F, BUDZELOVA K, OLAH M, MUSS C (2021) Late psychosocial consequencesfrom HIV to Covid. Clin Soc Work and Health Interv.12.2021.2.6-7.10.22359/cswhi_12_2_15.

21. UEMO (2019) Finland And Estonia Pioneering Cross-Border Health Services - Uemo. Uemo. Eu. Retrievable from: https://www. uemo.eu/finland-and-estonia-pioneeringcross-border-health-services/. 